metres of all instruments according to the metric, or the French scale is practically identical with the number marked upon the handle of the instrument-that is to say, that for all practical purposes a urethra which will just admit a No. 30 French scale, may be taken to have a circumference of thirty millimetres. For this reason, and also from the fact that while the successive instruments of the English scale are separated from each other by intervals of varied length, the sizes of the French scale proceed regularly by a constant increment of one millimetre in circumference, the former has been virtually abandoned in favour of the latter by all surgeons of the modern school who have much to do with stricture cases. Such being the case, it follows that any plane perpendicular to the axis of the urethra may be represented by the point of intersection of a vertical and a horizontal line upon the chart, both as regards the calibre of the urethra in that plane and its distance from the meatus respectively. By measuring a sufficient number of such consecutive planes in the urethra with the exploring bulb, or if the meatus is contracted, with the urethrometer, marking these points upon the chart, and joining them, a diagrammatic representation of the urethra will be obtained, which obviously conveys at a

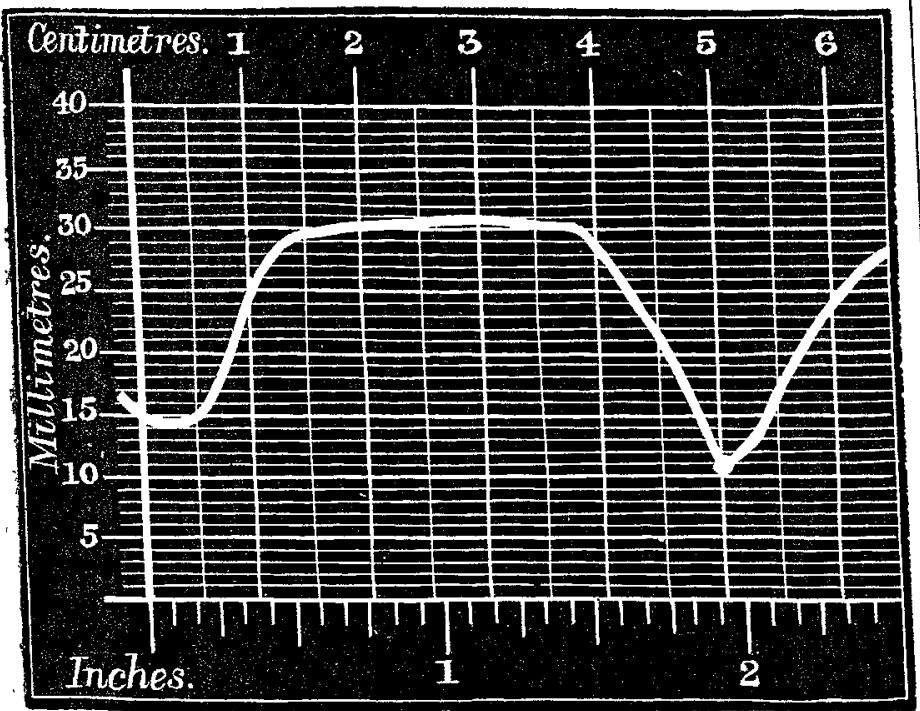

glance a more distinct idea of that canal in its totality than any written description could possibly do. The normal calibre of the urethra should be ascertained either by the ratio that $U$ tis has demonstrated to exist between the circumference of the flaccid penis and that of the urethra, or preferably by means of the urethrometer, and filled in upon the chart between the points of contraction. As an example the woodcut represents a urethra of a normal calibre of thirty millimetres with a meatus contracted to just admit a No. 15 bulb, this contraction extending to a depth of half a centimetre. Another stricture defined by a No. 10 bulb is present at five centimetres from the orifice, the urethra between these points expauding to its ascertained normal calibre of thirty millimetres.

There are two points in urethral pathology which are yet unsettled - namely, the average normal calibre of a healthy urethra, and the locality of the greatest frequency of stricture. I hope that these charts, by affurding a ready means for the accurate recording and comparison of uretbral measurements, may remove some of the obstacles to the accumulation of the data necessary to solve these important problems.

Moorgate-street, E.C.

\section{COMPLETE ABSENCE OF JEJUNUM, ILEUM, AND THE GREATER PART OF THE COLON.}

BY WILLTAM THOMAS, F.R.C.S., PROFESSOR OF ANATOMY, QUEEN'S COLLEGE; SURGEON TO THE F ANATOMY, QUEEN'S COLLEGE; SURG
CHILDREN'S HOSPITAL, BIRMINGHAM.

F. D-, aged two days, was sent to me by Dr. Richards on October 20th. The child had been born prematurely (seven months), and on examination no trace of anus was visible in the normal situation. The labia were comparatively large; on separation no urethral orifice was visible, but a probe passed in the direction of the urethra for about two ches could readily be felt through the abdominal wall bove the pubes, and was followed by the escape of a few pear fluid. A second could be passed along the perior wall of the vagina in the direction of the rectum for ore than three inches; this excited the expulsion of about teaspoonful of pale, yellowish, gelatinous mucus. The abdomen was not distended, and seemed smaller than normal, especially in the lower part. The child had taken the breast, ut had been sick continually, not retaining food many minutes. It was decided that come congenital malformation of the bowel existed and that no operative proeeding could be undertaken with a reasonable prospect of uccess.

Oct. 21st. - Worse ; cannot take the breast, but swallows a ittle milk and water. Has thrown up a quantity of stuff said to resemble "a baby's pale motion." The skin is much yellower than yesterday, and the child altogether weaker.22nd: The child gradually got weaker and died this morning. I was not immediately informed of the child's death, in consequence of which there was delay in obtaining permission to make a post-mortem. The examination had to be made within an hour of the time appointed for the funeral, and was not so complete as desirable, only the abdominal viscera being examined.

The following notes were taken by Dr. Powell, resident medical officer at the Children's Hospital, who kindly assisted me:-Rigor mortis almost absent; skin generally of a brownish-yellow, with a considerable amount of post-mortem lividity. On opening the abdomen, and prolonging the incision downwards, it was found there was no union of the pubic bones, an interval existing between them large enough to admit a finger. There was no great distension of the abdomen; the great omentum was adherent in various places to the parts beneath. The stomach was of normal size, moderately distended, and connected with the duodenum by a constricted pylorus half an inch in length and rather less in diameter. On raising the great omentum the duodenum was found to occupy the greater part of the abdominal cavity. It was about an inch and a half in diameter in the distended state, and curved round the pancreas, to terminate on the left side of the spine by a blind extremity. There was no trace of any other part of the small intestine, nor of the cæcum, ascending or transverse colon. The intestine was recommenced by a blind portion of descending colon lying on the lower end of the left kidney, and continued by a sigmoid flexure and rectum, to terminate in the vagina The liver was of normal size; the gall-bladder contained bile, but was not distended. There was nothing unusual about the kidneys, spleen, or pancreas.

Birmingham.

\section{CASES IN MIDWIFERY PRACTICE.}

\section{BY J. R. FORREST, M.R.C.S., \&c.}

PREGNANCY IN A PATIENT WITH FIBROID TUMOUR OF THE UTERUS.

MRs. W—, aged twenty-four, a primipara, was attended by me in her confinement. She was a healthy-looking woman, who said she had never suffered from any serious illness. She had a sister who died nine days after bearing her first child, death being attributed to suppression of the lochia. Her mother, still living, always had difficult labours. My patient was taken in labour about 2 P.M. I was summoned at $10 \mathrm{P} . \mathrm{M}$., and found the pains returning at intervals of about ten minutes. Abdominal palpation revealed the outline of the spine of the child with the concavity to the right, but the breech was not to be discerned. Towards the fundus of the uterus, and on the right side, a hard rounded swelling, dull on percussion, of the size of the foetal head, could be made out, but on examination per vaginam the head could be felt presenting in the first position. The os uteri was dilated to the size of half a crown on my arrival, the anterior portion of the cervix capping the foetal head, so that the os was carried far towards the sacrum. The cervix proving extremely rigid, I introduced a Barnes' bag (No. 1), and then No. 2. The liquor amnii was greatly pent-up by the foetal head, so, puncturing the membranes, $I$ introduced one blade of the torceps, and using this as a vecti , I succeeded in pushing aside the valve formed by the cervix. From the result of my previous examination by abdoninal palpation I felt sure that all was not right, 
and the presence of a uterine tumour suggested itself / him at intervals for the last ten or twelve years; sometimes to my mind. Fearing hæmorrhage from this source, I gave repeated dracbm-doses of liquid extract of ergot, and the head being long delayed in the second stage of labour, I introduced the second blade of the forceps. Extraction was a matter of great difficulty, and I believed that a chief cause of the delay was the distortion of the uterus caused by the abnormal growth. I therefore pushed the tumour towards the right side, and succeeded in extracting the child. The placenta was removed without difficulty, and after its removal the hard swelling previously mentioned was still to be felt. Was there a second child still in the uterus? Of course the rounded swelling observed on my first examination might have been due to this cause, but I did not believe it was, for it was, although hard, not so hard as the head or breech would have been, and its outline was not so distinctly circumscribed as either of these. To make my diagnosis sure, I introduced my hand into the vagina, when the cavity of the uterus was felt to be empty, and on bimanual examination the tumour was found to move with the rest of the uterus. It was free from surrounding adhesions. Most fortunately there was little or no hæmorrhage. I subsequently learnt that my patient had had but little difficulty before her confinement in passing either urine or fæces, but the discharge was great at her monthly periods, and was not regular, the menstrual flow often reappearing after a fortnight. She likewise informed me that she had for months suffered from an intermittent darting pain about the hypogastric and right inguinal regions. With the exception of some soreness of the nipples, she made a good recovery, and the growth very rapidly diminished in size. No doubt a great deal of the difficulty of her case was due to the obstacle which the tumour formed to the equable contraction of the uterus, and this difficulty would perhaps be increased by the administration of ergot; but I think that in the case of a rapidly growing uterine tumour in a young woman, there would probably be a large excess of muscular tissue in its structure, and that the ergot would hence act very beneficially in preventing hæmorrhage.

\section{ABORTION OCCURRING IN A WOMAN THE SUBJECT OF} RECURRENT CARCINOMA OF THE BREAST.

Mrs. S-, aged forty three, had her left breast removed at the Hull Infirmary last Easter. She came under my care at the beginning of August last, and then presented such an enlargement of the axillary glands, and the integumentary and muscular structures were so involved, as to hold out no hope of relief from further operation. I did not know that she was pregnant, and she afterwards informed me that she was not aware of her condition herself; but at the beginning of last November she miscarried, and a fœetus of about four months was the result. My patient recovered from the miscarriage, but died from general exhaustion in about a fortnight, the cancerous mass having become widely spread.

Brandesburton, Hull.

\section{d}

\section{HOSPITAL PRACTICE。 BRITISH AND FOREIGN.}

Nalla antem estalia procerto noscendi via, nisi quamplurimas et morborum etdissectionum historias, tum aliorum tum proprias collectas habere, et inter se comparare.-Morgagri De Sed, et Caus, Nhorb., lib. iv. Procmium.

\section{ST. THOMAS'S HOSPITAL.}

REMOVAL OF CALCULUS OF BLADDER BY LITHOTRITY IN A BOY AGED SIXTEEN ; CURE.

(Under the care of Mr. SYDNEY JoNES.)

A. W. P-, aged sixteen, was admitted on March 12th, 1883.

On admission, he complained of pain in the perineum on passing urine, and that the stream was sometimes suddenly stopped; some days he had had to pass water very frequently, and had a smarting pain behind the pubes on walking. He had never passed blood, but the water was sometimes thick. On further questioning he gave a history of pain in the left side over the kidney, which had troubled

this had been severe and accompanied by vomiting, but has had only slight pain (if any) in the left side for the last six months. The urine was of sp. gr. 1015, did not contain blood, pus, or albumen. Microscopical examination revealed nothing beyond a few amorphous phosphates and epithelial scales. The day after admission he was sounded and a hard stone was struck. On the following day Mr. Sydney Jones performed lithotrity with a medium-sized lithotrite, the stone being caught and crushed in successive portions, the bladder was then washed out with Bigelow's apparatus. The fragments were almost black with a partial white in. crustation. Upon the surface they were very hard, composed for the most part of calcium oxalate, and weighed 240 grains. There was no hæmorrhage, and the operation was concluded in less than half an hour. A half-grain morphia suppository was introduced after the operation. He was allowed to get up in a couple of days.

March 15th. - The patient has complained of but little pain, and the urine has been quite clear; it is slightly acid, and deposits a slight sediment, which when examined shows a few typical oxalate of lime crystals.

The temperature went up to $102^{\circ}$ on the evening of operation, but was normal before and after that observation. There were no further symptoms.

\section{VICTORTA PARK CHEST HOSPITAL.}

CASE OF EMPYEMA OF TWELVE MONTHS' STANDING, WHICH HAD OPENED EXTERNALLY AND THROUGH THE LUNG CURED IN FIVE WEEKS BY FREE INCISION; REMARKS.

\section{(Under the care of Dr. SAMUEL WEST.)}

GEORGE T. N-, aged twenty, a soldier, was admitted for discharging empyema. He had never been laid up with any illness until January, 1882, when he was suddenly seized with pain in the left side, a troublesome cough without much expectoration, and shortness of breath. He was laid up in for two months, and he recovered, as he believed, completely. He remained well until June, 1882, when he noticed a hard lump in the front of the upper part of the chest. It was very painful, and after his admission into the hospital it was incised. About two pints of greenish. coloured matter escaped. This is the opening from which pus still continues to run.

On admission into the hospital in December, 1882, his condition was as follows:- He was a well-built, strong young man, rather thin, but looking healthy, and with a ruddy complexion. The fingers of both hands were markedly clubbed, the wrists of great size, but of normal development. The left side of his chest was bulging in the lower part, but flattened beneath the clavicle. Respiratory movement and voice and breath sounds, as well as vocal vibrations, were completely absent below the second rib, the heart was displaced, so that the dulness reached to nearly two inches to the right of the sternum, and the apex probably lay immediately beneath the sternum. At the left apex the percussion was only slightly impaired, the breath sounds were audible, and the expiration prolonged. In the second inter. costal space, an inch and a half from the sternum, was a fistulous opening, from which pus slowly escaped. This was the seat of the incision referred to. The patient expectorated daily about three-quarters of a pint of sweet pus, as he had done since June (six months). The urine was acid and contained no albumen. The diagnosis was made of an empyema of at least six months' duration, which was discharging partly through the lung and partly by the external opening. The patient was kept under observation for three weeks, during which time the temperature was never raised, and the amount of expectoration did not diminish.

Paracentesis was then performed with an aspirator in the fifth space in the third axillary line and twenty-three ounces of laudable pus were removed. A little air came through the aspirator at the end of the operation, and on removing the cannula some was heard to rush into the chest through the upper opening. The whole side became semi-resonant and breath sounds were heard over the whole front and in the axilla. This was probably due to the passage of air in and out through the pulmonary fistula, so that the case had been 